\title{
Educational Activities for Rural and Urban Students to Prevent Skin Cancer in Rio Grande do Sul, Brazil
}

\author{
Kelle Velasques, Luana Roberta Michels, Leticia Marques Colome, Sandra Elisa \\ Haas*
}

\begin{abstract}
Background: Excessive exposure to the sun during childhood is strongly associated with the development of skin cancer in the future. The only way to prevent the development of skin cancer is to protect against ultraviolet radiation, which can be achieved through strategic awareness during childhood and adolescence. Objective. The aim of this work was to evaluate the impact of educational activities for rural and urban students to promote the use of sunscreens and prevent skin cancer. Materials and Methods: This study was carried out with students (9-12 years) of rural $(n=70)$ and urban $(n=70)$ schools in Rio Grande do Sul state, Brazil. The educational interventions were lectures and games. The impact of this strategy was evaluated through the application of a questionnaire before and after the interventions. Results: Before the intervention, it was found around 50\% of rural and urban students were not aware of the damage caused by sun exposure, often exposing themselves to UV radiation without use sunscreen $(\sim 25 \%)$ and at the most critical times of the day/year. After the lectures we observed an improvement in the behavior of the students with regard to sun exposure and knowledge about skin cancer. Conclusions: The results of this study emphasize the importance of prevention strategies for skin cancer and promoting the use of sunscreens based educational strategies. The interventions were of great value in relation to disseminating knowledge on the subject.
\end{abstract}

Keywords: Children - skin cancer - sun exposure - sunscreen - educational intervention

Asian Pac J Cancer Prev, 17 (3), 1201-1207

\section{Introduction}

The incidence of skin cancer has been increasing alarmingly in recent years and is becoming a serious public health problem since it affects the quality of life of the patients. According to the Brazilian National Cancer Institute skin cancer, which can be caused by exposure to solar radiation, is the cancer with the highest incidence in Brazil and it can occur in all skin types and at any age (INCA, 2014a). In Brazil, the non-melanoma skin cancer is more common in men in the South $(159.51 / 100.000)$, Southeast (133.48/100.000) and Midwest (110.94/100.000 inhabitants) regions. In the Northeast (40.37/100.000) and North (28.34/100.000) regions, is in the second position. In women, the most frequent in all regions, with a risk estimate of 112.28/100.000 in the Southeast, 99.31/100.000 in the Midwest, 86.03/100.000 in the South, $46.68 / 100.000$ in the Northeast and 24.73/100.000 in the North. As for melanoma, its lethality is high, but its incidence is low (2.960 new cases in men and 2.930 in women) (INCA, 2014a).

In recent decades, knowledge concerning the etiology of skin cancer has expanded and it has been identified that ultraviolet radiation is a major factor involved (Agbai et al., 2014). Due to the cumulative effect of radiation the skin can suffer ill effects such as aging and cell changes which, through genetic mutations, predispose the skin to cancer (Stolzel, 2014). The Brazilian Society of Dermatology states that preventing overexposure to the sun and protecting your skin from the effects of UV radiation are the best strategies for the prevention of melanoma and other skin tumors (Dermatology, 2014; Foletto, 2014).

Although prevention campaigns emphasize the risks of sun exposure, data in the literature show that is low the number of teenagers who sunbathe apply sunscreen or wear a hat and shirt, and thus many are overly exposed to radiation during the summer (Castilho, 2010; Quatrano, 2013). The prevention of skin cancer during childhood/ adolescence is of fundamental importance since at this age people tend to remain outdoors a great deal of the time, and many intentionally seek a tan without any means of photoprotection (Crane et al., 2012; Gilaberte and Carrascosa, 2014). A child needs to suffer sunburn only twice for the risk of basal cell carcinoma to increase. Overexposure to sunlight can also contribute to the development of nevi, one of the early indicators of melanoma (Hunter et al., 2010).

According to Sattler (2014), factors associated with low adherence to sun protection behavior were age 
below 20 or over 64 years, male sex, lower knowledge about accurate sun protection recommendations and UVassociated risks and low UV-exposure (Sattler et al., 2014). The only way to prevent the skin cancer is protection against ultraviolet radiation, which can be achieved through awareness strategies starting from childhood and adolescence. Children need greater care regarding protection as they have the thinnest and most sensitive skin and they have a longer time available to develop adverse effects, besides spending more time performing outdoor activities and being unaware of the risk to which they are exposed (Gilaberte and Carrascosa, 2014).

Young people, in particular, constitute a vulnerable group associated with inappropriate exposure to sunlight, influenced by both aesthetic factors and a greater duration of physical activity performed outdoors (Kyle et al., 2014). The security measures that must be undertaken from childhood include the use of sunscreen, protective clothing (hats, long sleeves and sunglasses), staying in the shade, and limiting outdoor activities during peak incidence of UV rays (Hunter et al., 2010). Besides that, the parental behavior is important determinant of the children protection(Gefeller et al., 2014; Klostermann and Bolte, 2014). Generally, parents protect your son with single measures, as cited above, however, the combined and correct use of multiple sun protection is essential and not occurs (Klostermann and Bolte, 2014).

Agriculture is an extremely hazardous industry associated with a large number of occupational injuries and chronic illnesses. Farmers had a more than a 2-fold risk of basal cell carcinoma (Marehbian et al., 2007), because the sun exposure. In Brazil, 20.7\% of population works at agriculture activities (INCA, 2014b). Children living in rural areas are expected to be more exposed to sunlight than those in urban areas due to several factors. Among these is the fact that the journey to school is generally longer and is often made without any means of transport, the influence of the working routine of the parents in the countryside and the leisure activities that these children indulge in.

In Brazil, the highest estimated rates in men and women are in the South. Considering this fact, the Rio Grande do Sul State of Brazil legislated the legal rule n. 13.469/2011 of (State, 2011), which provides for the prevention and combating of sun exposure associated with diseases in rural workers, measures to reduce the exposure of rural workers to the sun. According this regulation, preventive measures should be deployed during periods of the day with the highest incidence of irradiation, contributing to the practice of the use of sunscreens, encouraging people to undergo screening tests for cancer and other skin diseases and promoting educational campaigns aimed at educating the public regarding the care and procedures to be adopted when activities involving sun exposure are performed.

An understanding of the sun exposure habits of children and adolescents in rural and urban areas is also important because it is through this knowledge that programs to prevent skin cancer have been successful. In this regard, it is necessary to implement effective prevention strategies and enhance an awareness of appropriate behavior for young people in relation to sun exposure, encouraging them to use sunscreens and other physical means of sun protection. Furthermore, it is known that the habits adopted by children and adolescents are greatly influenced by the routine of their parents. Thus, this study aims to develop strategies for the prevention of skin cancer and adoption of the use of sunscreens in children attending rural and urban schools in Uruguaiana, Rio Grande do Sul State, Brazil and to evaluate the influence of educational interventions with regard to sun exposure and protection.

Table 1. Questions Related to the Knowledge and Habits of Students Attending Rural and Urban Schools before the Intervention

\begin{tabular}{|c|c|c|c|}
\hline Questions & Urban $(\%)$ & Rural (\%) & $\mathrm{p}$ \\
\hline Do you know what ultraviolet radiation is? (Yes) & 10 & 11.4 & 0.063 \\
\hline Can the sun be harmful to your health? (Yes) & 62.9 & 75.7 & 0.185 \\
\hline \multicolumn{4}{|l|}{ What are the safest times o be in the sun? } \\
\hline Before 10 am and after $4 \mathrm{pm}$ & 27.1 & 27.1 & 0.561 \\
\hline At noon & 25.7 & 28.6 & 0.561 \\
\hline At $2 \mathrm{pm}$ & 47.1 & 44.3 & 0.561 \\
\hline Do you know how to correctly protect yourself from the sun? (Yes) & 81.4 & 80 & 0.065 \\
\hline Can excessive exposure to the sun cause skin cancer? (Yes) & 78.6 & 97.1 & 0.318 \\
\hline Do you know what skin cancer is? (Yes) & 51.4 & 37.1 & 0.222 \\
\hline Are marks on the skin that change size or color symptoms of skin cancer? (Yes) & 78.6 & 91.4 & 0.088 \\
\hline Are skin sores that itch, bleed and do not heal symptoms of skin cancer? (Yes) & 65.7 & 81.4 & 0.100 \\
\hline Do you generally spend much time in the sun? (Yes) & 45.7 & 61.4 & 0.438 \\
\hline Do you usually use sunscreen? (Yes) & 22.9 & 25.7 & 0.564 \\
\hline \multicolumn{4}{|l|}{ What time of the year do you use sunscreen? } \\
\hline Never & 25.7 & 34.3 & 0.278 \\
\hline Only in summer & 65.7 & 54.3 & 0.278 \\
\hline All year round & 8.6 & 11.4 & 0.278 \\
\hline When exposed to the sun do you wear a hat/cap or use an umbrella? (Yes) & 62.9 & 72.9 & 0.253 \\
\hline Do you wear sunglasses? (Yes) & 47.1 & 45.7 & 0.272 \\
\hline
\end{tabular}

${ }^{*} \mathrm{p}>0.05$ : There is no significant difference $; \mathrm{p}<0.05$ : There is a significant difference 


\section{Materials and Methods}

This project was approved by the Ethics Committee in Research of the Federal University of Pampa (UNIPAMPA), registered under number 045-2011. Initially, we applied a questionnaire totaling 29 questions to assess the level of knowledge of the students. Data collection was conducted with 70 students attending three rural schools and 70 students attending two urban schools, in fourth and fifth year classes. The students being aged between 9 and 12 years. The questions addressed issues concerning sun exposure habits and knowledge regarding skin cancer and sunscreen use. After evaluating the results of the questionnaire, two types of intervention that were applied equally to all students were prepared. The first intervention was to give a lecture to students addressing the main issues associated with sun protection, skin care and methods of photoprotection and to provide details on skin cancer and how to identify it through the signs and symptoms. Information on the correct way to apply sunscreen, both in terms of distribution and quantity, and then a word search game, memory game, hints game and a board game were played. At the end of the lectures the reapplication of the questionnaire was performed. The questionnaire was administered in schools after signing the consent form.

Statistical analysis was performed descriptively with use of absolute (n) and relative (\%) frequencies from the data tabulated using SPSS (Statistical Package for Social Sciences) and with the use of the chi-square association test.

\section{Games applied}

Word searches: This game consists of presenting an array of letters in horizontal and vertical lines, which form words that can be arranged horizontally or vertically. The player must find and mark the words that were studied
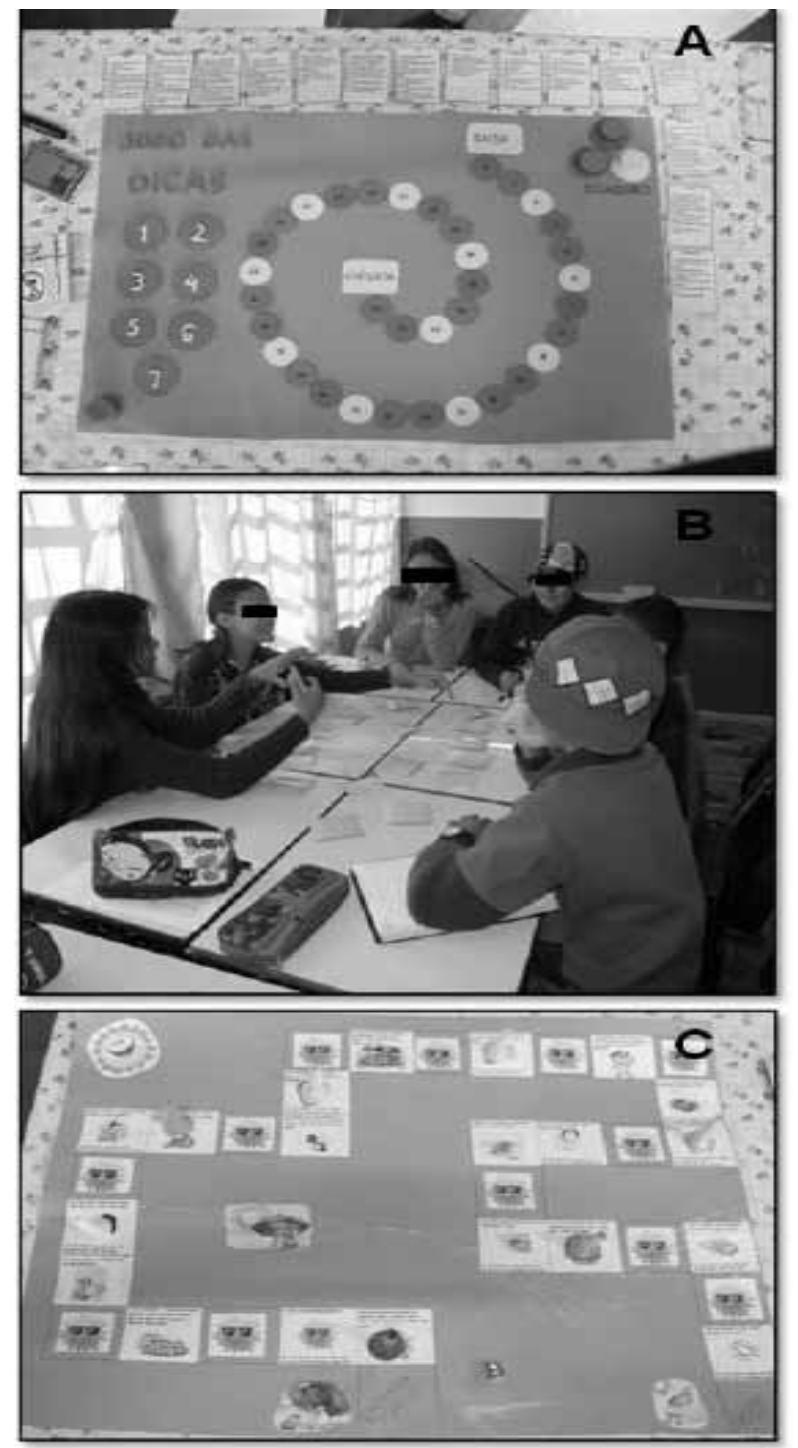

Figure 1. Hints game (A), Memory game (B), Board game (C)

Table 2. Questions Concerning the Students' Knowledge before and after the Intervention

\begin{tabular}{|c|c|c|c|c|}
\hline Questions & Rural x Rural (\% & $\mathrm{p}$ & UrbanxUrban (\%) & $\mathrm{p}$ \\
\hline \multicolumn{5}{|l|}{ Do you know what ultraviolet radiation is? } \\
\hline (Yes) & $11.4 \times 74.3$ & 0.002 & $10 \times 60$ & 0.329 \\
\hline \multicolumn{5}{|l|}{ Do you have a good knowledge of the effects of solar radiation on the skin? } \\
\hline (Yes) & $48.6 \times 80$ & 0.282 & $38.6 \times 78.6$ & 0.285 \\
\hline \multicolumn{5}{|l|}{ Can the sun be harmful to your health? } \\
\hline (Yes) & $75.7 \times 94.3$ & 0.217 & $62.9 \times 97.1$ & 0.146 \\
\hline \multicolumn{5}{|l|}{ What are the safest times to be in the sun? } \\
\hline Before 10 am and after $4 \mathrm{pm}$ & $27.1 \times 58.6$ & 0.004 & $27.1 \times 64.3$ & 0.136 \\
\hline At noon & $28.6 \times 12.9$ & 0.004 & $25.7 \times 4.3$ & 0.136 \\
\hline At $2 \mathrm{pm}$ & $44.3 \times 28.6$ & 0.004 & $47.1 \times 31.4$ & 0.136 \\
\hline \multicolumn{5}{|l|}{ Do you know how to correctly protect yourself from the sun? } \\
\hline (Yes) & $80 \times 97.1$ & 0.282 & $81.4 \times 93.3$ & 0.116 \\
\hline \multicolumn{5}{|l|}{ Can excessive exposure to the sun cause skin cancer? } \\
\hline (Yes) & $97.1 \times 98.6$ & 0.030 & $78.6 \times 87.1$ & 0.351 \\
\hline \multicolumn{5}{|l|}{ Do you know what skin cancer is? } \\
\hline (Yes) & $37.1 \times 92.9$ & 0.272 & $51.4 \times 88.6$ & 0.402 \\
\hline \multicolumn{5}{|l|}{ Are marks on the skin that change in size or color symptoms of skin cancer? } \\
\hline (Yes) & $91.4 \times 85.7$ & 0.296 & $78.6 \times 80$ & 0.466 \\
\hline $\begin{array}{l}\text { Are skin sores that itch, bleed and do not heal symptoms of skin cancer? } \\
\text { (Yes) }\end{array}$ & $81.4 \times 90$ & 0.183 & $65.7 \times 81.4$ & 0.088 \\
\hline
\end{tabular}


(such as sunscreen, sunglasses, sun, skin cancer, ultraviolet radiation and photoprotection).

Hints game: The mediator has at hand cards containing seven tips for different words/terms (Figure 1A). Each player is read a tip and then they must guess the word/ term in question. The player who guesses correctly the highest number of words wins the round. The words/terms included: summer, sunglasses, sunscreen, sun umbrella, skin cancer, sunburn, water, self-examination of the skin and SPF.

Memory game: This game consists of sheets that have pictures on one side. The pictures are repeated on two different sheets and photoprotection is the subject, to emphasize the danger of overexposure and the methods of protection (Figure 1B). The pictures include sunscreen, sun protection factor (SPF), sunburn, skin cancer and sunglasses. To start the game, the sheets are placed on the table facing down so that they cannot be seen. Each participant must, in turn, flip over two sheets and let everyone see the pictures. If the pictures are the same, the participant collects them up and plays again. If they are different, they turn them back over and the next participant plays. The participant who has collected the most pairs of pictures when they have all been collected wins the game.

Board game: The board is composed of squares and each square contains a question regarding a certain theme. Initially, each player chooses a cone with a distinct color to identify themselves and then they throw the dice to move to the appropriate square (Figure 1C). The mediator reads the corresponding home asks if the player hits the question can walk several houses, but if you miss or even getting back the player misses a round. The questions were related to the topic such as: Do you know what ultraviolet radiation is? What are the safest times to be in the sun? What are the signs and symptoms of skin cancer? Which $\mathrm{SPF}$ is the most appropriate for use?

\section{Results and Discussion}

The study was conducted at rural and urban schools with 140 elementary school students of between 9 and 12 years of age by applying a questionnaire. The objective was to assess the awareness of the children regarding protection against solar radiation and subsequently to evaluate the influence of the educational activities and identify any differences between the two types of schools.

Firstly, the initial data collected from the urban and rural schools were compared, as shown in Table 1, and no significant difference was observed ( $p$ values $>0.05$ ) for all questions. This result demonstrates that the level of knowledge of the students interviewed at the rural and urban schools was the same, indicating that the sample was homogeneous at baseline, i.e., there was no significant difference between groups.

Table 3. Questions Related to the Habits of the Students before and after Intervention

\begin{tabular}{|c|c|c|c|c|}
\hline Questions & Rural x Rural (\%) & $\mathrm{p}$ & Urban x Urban (\%) & $\mathrm{p}$ \\
\hline $\begin{array}{l}\text { Do you generally spend much time in the sun? } \\
\text { (Yes) }\end{array}$ & $61.4 \times 42.9$ & 0.080 & $45.7 \times 50$ & 0.016 \\
\hline $\begin{array}{l}\text { Do you usually use sunscreen? } \\
\text { (Yes) }\end{array}$ & $25.7 \times 47.1$ & 0.071 & $22.9 \times 42.9$ & 0.432 \\
\hline $\begin{array}{l}\text { How often do you reapply sunscreen? } \\
\text { Never } \\
\text { Once } \\
\text { More than once }\end{array}$ & $\begin{array}{r}57.7 \times 42.2 \\
5.4 \times 15.4 \\
26.9 \times 42.3\end{array}$ & $\begin{array}{l}0.010 \\
0.010 \\
0.010\end{array}$ & $\begin{array}{l}47.5 \times 50.8 \\
37.7 \times 18 \\
14.8 \times 31.1\end{array}$ & $\begin{array}{l}0.540 \\
0.540 \\
0.540\end{array}$ \\
\hline $\begin{array}{l}\text { What time of the year do you use sunscreen? } \\
\text { Never } \\
\text { Only in summer } \\
\text { All year round }\end{array}$ & $\begin{array}{l}34.3 \times 30 \\
54.3 \times 48 \\
11.4 \times 20\end{array}$ & $\begin{array}{l}0.365 \\
0.365 \\
0.365\end{array}$ & $\begin{array}{l}25.7 \times 30 \\
65.7 \times 48.6 \\
8.6 \times 21.4\end{array}$ & $\begin{array}{l}0.993 \\
0.993 \\
0.993\end{array}$ \\
\hline $\begin{array}{l}\text { When exposed to the sun do you wear a hat/cap or use an umbrella? } \\
\text { (Yes) }\end{array}$ & $72.9 \times 71.4$ & 0.217 & $62.9 \times 75.7$ & 0.448 \\
\hline $\begin{array}{l}\text { Do you wear sunglasses? } \\
\text { (Yes) }\end{array}$ & $45.7 \times 45.7$ & 0.253 & $47.1 \times 47.1$ & 0.660 \\
\hline
\end{tabular}

Table 4. Issues Relating to Risk Factors for Students before and after the Intervention in Rural and Urban Schools

\begin{tabular}{|c|c|c|c|c|}
\hline Questions & Rural x Rural (\%) & $\mathrm{P}$ & Urban x Urban (\%) & $\mathrm{P}$ \\
\hline $\begin{array}{l}\text { At their workplace, are your parents exposed to the sun? } \\
\text { (Yes) }\end{array}$ & $78.6 \times 78.6$ & 0.879 & $41.4 \times 45.7$ & 0.376 \\
\hline $\begin{array}{l}\text { Do your parents use sunscreenwhen out in the sun? } \\
\text { (Yes) }\end{array}$ & $32.9 \times 52.9$ & 0.161 & $45.7 \times 60$ & 0.010 \\
\hline $\begin{array}{l}\text { In your free time do you accompany your parents to work? } \\
\text { (Yes) }\end{array}$ & $55.7 \times 54.3$ & 0.064 & $34.8 \times 52.2$ & 0.202 \\
\hline $\begin{array}{l}\text { If the answer to the above question is "yes" do you use sunscreen? } \\
\text { (Yes) }\end{array}$ & $43.1 \times 68.6$ & 0.302 & $15.7 \times 41.2$ & 0.230 \\
\hline $\begin{array}{l}\text { Has anyone in your family ever had skin cancer? } \\
\text { (Yes) } \\
\text { No }\end{array}$ & $\begin{array}{c}4.3 \times 8.6 \\
55.7 \times 54.3\end{array}$ & $\begin{array}{l}0.203 \\
0.203\end{array}$ & $\begin{array}{c}7.1 \times 4.3 \\
51.4 \times 52.9\end{array}$ & $\begin{array}{l}0.730 \\
0.730\end{array}$ \\
\hline $\begin{array}{l}\text { Have you experienced any type of sunburn after sun exposure? } \\
\text { (Yes) }\end{array}$ & $40 \times 37.1$ & 0.024 & $41.4 \times 42.9$ & 0.676 \\
\hline
\end{tabular}


Table 5. Questions Regarding the Knowledge and Habits of Students from Rural and Urban Schools after Intervention

\begin{tabular}{|c|c|c|c|}
\hline Questions & Urban $(\%)$ & Rural (\%) & $\mathrm{P}$ \\
\hline \multicolumn{4}{|c|}{ Do you know what ultraviolet radiation is? } \\
\hline (Yes) & 60 & 74.3 & 0.199 \\
\hline \multicolumn{4}{|c|}{ Can the sun be harmful to your health? } \\
\hline (Yes) & 97.1 & 94.3 & 0.125 \\
\hline \multicolumn{4}{|c|}{ What are the safest times to be in the sun? } \\
\hline Before 10 am and after $4 \mathrm{pm}$ & 64.3 & 58.6 & 0.023 \\
\hline At noon & 4.3 & 12.9 & 0.023 \\
\hline At $2 \mathrm{pm}$ & 31.4 & 28.6 & 0.023 \\
\hline \multicolumn{4}{|c|}{ Do you know how to correctly protect yourself from the sun? } \\
\hline (Yes) & 93.3 & 97.1 & 0.125 \\
\hline \multicolumn{4}{|c|}{ Can excessive exposure to the sun can cause skin cancer? } \\
\hline (Yes) & 87.1 & 98.6 & 0.015 \\
\hline \multicolumn{4}{|l|}{ Do you know what skin cancer is? } \\
\hline (Yes) & 88.6 & 92.9 & 0.405 \\
\hline $\begin{array}{l}\text { Are marks on the skin that change } \\
\text { (Yes) }\end{array}$ & \multicolumn{2}{|c|}{ Are marks on the skin that change in size or color symptoms of skin cancer? } & 0.393 \\
\hline $\begin{array}{l}\text { Are skin sores that itch, bleed and } \\
\text { (Yes) }\end{array}$ & \multicolumn{2}{|c|}{ Are skin sores that itch, bleed and do not heal symptoms of skin cancer? } & 0.094 \\
\hline \multicolumn{4}{|c|}{ Do you generally spend much time in the sun? } \\
\hline \multicolumn{4}{|l|}{ Do you usually use sunscreen? } \\
\hline \multicolumn{4}{|c|}{ What time of the year you use sunscreen? } \\
\hline Never & 30 & 30 & 0.888 \\
\hline Only in summer & 48.6 & 48 & 0.888 \\
\hline All year round & 21.4 & 20 & 0.888 \\
\hline $\begin{array}{l}\text { When exposed to the sun do you v } \\
\text { (Yes) }\end{array}$ & 75.7 & 71.4 & 0.456 \\
\hline \multicolumn{3}{|l|}{ Do you wear sunglasses? } & 0.660 \\
\hline
\end{tabular}

Evaluation of the results obtained by students in rural schools before and after the interventions

When asked about their knowledge of ultraviolet radiation before the interventions, only $11 \%$ of students responded that they understood the term and knew that ultraviolet radiation is one of the key players in the development of skin cancer (Rhee et al., 2004). This percentage increased significantly after the intervention $(\mathrm{p}=0.002)$, with approximately $70 \%$ of students from rural schools having a knowledge of ultraviolet radiation.

A worrying statistic was that related to knowing the appropriate sun exposure times. As the data in Table $2 \mathrm{v}$ show, many students $(72.9 \%)$ could not correctly answer the question regarding the safest times of the day for sun exposure. However, after the intervention, there was a significant increase in students who answered 'before 10 am and after 4 pm' $(58.6 \%, p=0.004)$ and a decrease in the choice of the wrong answers to the question (at noon and at $2 \mathrm{pm}$ ).

In relation to their knowledge regarding skin cancer, few students $(37.1 \%)$ reported knowing what skin cancer is. According to Table 2, after the intervention there was an increase in positive responses $(92.9 \%)$, which indicates that the strategy used to develop student learning on the topic was effective.

On reapplication of the questionnaire, when asked if excessive sun exposure could cause skin cancer both in adults and in children, $98.6 \%$ of the students answered "yes". A study by Fernandes and Marcomini (Fernandes, 2006), with students from elementary and high schools, showed that most students had heard about skin cancer and knew that ultraviolet radiation was the main factor which causes this disease.

As Table 3 shows, the students' habits in relation to sun exposure during play time or on their way to school were inappropriate in the majority of cases $(61.4 \%, \mathrm{p}=$ $0.080)$. When ultraviolet $B$ radiation is more intense the risk of developing cancer skin in the future is higher, since this disease develops in multiple steps due to the action of external factors, and ultraviolet radiation from the sun is the main factor (Rhee et al., 2004).

It was observed that most of the students do not use sunscreen daily, since approximately $75 \%$ do not use sunscreen for general activities and when practicing outdoor sports, as verified in other studies. Although not significant, there was a decrease in this percentage after the intervention, since $47 \%$ started using sunscreen daily. Around $55 \%$ of the students used sunscreen in only in the summer. However, UVA radiation, which predisposes the skin to the development of skin cancer, has a constant intensity throughout the year, affecting the skin to similar extents during winter and summer (Kyle et al., 2014).

Sunscreens should be applied before exposure to the sun throughout the body in adequate quantities. One of the 
guidelines on the label is the need to reapply the product every 2 hours (Jansen et al., 2013). The reasons for this are to complement the amount used initially in order to reach an SPF close to that specified on the label and to replace the amount that may have been removed by water, sweat or friction with a towel, clothes or the sand (Quatrano, 2013). In the present study, only $26.9 \%$ of students answered that they reapplied sunscreen more than once. After the lectures this number increased significantly $(\mathrm{p}=0.010)$ to $42.3 \%$.

The practice of accompanying parents to work was more prevalent among students from urban schools with around 55\% accompanying their parents to work without sunscreen. However, after the interventions they accompanied their parents with the use of sunscreen.

\section{Evaluation of the results obtained by students in urban schools before and after the interventions}

Of the 70 students in urban schools, $55(78.6 \%)$ demonstrated awareness that the sun can be harmful to your health in certain situations, for example, in cases of excessive exposure. After the lectures, though not significant, this number increased to $61(87.1 \%)$ students (Table 2).

When asked what skin cancer is before the interventions only $51.4 \%$ of the students stated that they knew what it was, while after the interventions this percentage increase by $37.2 \%$ to a total of $88.6 \%$ of the students. In relation to the signs and symptoms, approximately $80 \%$ of the students recognized that it is important for students in this age group to have some knowledge regarding skin cancer, thus avoiding the future development of this disease, since its incidence has increased in recent decades.

In relation to the use of other physical means of sun protection, $75.7 \%$ of the students used hats, caps and an umbrella after the intervention compared with $62.9 \%$ who used these means of photoprotection before the intervention. Sunprotection was defined as the use of sunscreens, clothing, hats or caps (Gefeller et al., 2014; Gilaberte and Carrascosa, 2014). Individuals were asked about what measures they used to protect themselves against the sun and the most common measures of photoprotection were sunscreen $(92 \%)$, sunglasses $(63 \%)$ and hats $(50.5 \%)$ (Hora, 2003).

When initially asked if their parents used sunscreen when exposed to the sun, $45.7 \%$ of students answered "yes", and this number increased significantly to $60 \%$ $(\mathrm{p}=0.010)$ after the intervention, and can be seen in Table IV. This verifies the importance of educational activities, since the knowledge acquired by the students was passed on to their parents and an improvement in their behavior during sun exposure was observed.

According to Table $4,42.9 \%$ of the students surveyed reported previous episodes of sunburn. In a previous study involving college students, approximately $20 \%$ of the respondents $(n=76)$ reported a history of sunburn with blisters and the literature suggests that repeated episodes of sunburn or blistering double the risk of melanoma(Castilho, 2010). schools compared with those of urban schools after the same intervention

Students from both schools recognized the sun as being a harmful agent in relation to the skin, about $97 \%$ were aware that the sun can be harmful to health. The results of this study are in agreement with the data obtained by Santos and co-workers (2007) in relation to an awareness of skin damage related to overexposure to the sun where the results indicated that $59.6 \%(\mathrm{n}=119)$ of the respondents knew the consequences photodamage, and of these $40.8 \%(n=82)$ identified skin cancer as the primary dermatosis related to overexposure to the sun (Santos, 2007).

Regarding the safest time of the day for sun exposure, $64.3 \%$ of the students in urban schools said they knew the safest times for sun exposure were before 10 am and after $4 \mathrm{pm}$ and for the students in rural schools this figure was $58.6 \%$, with a significant difference when compared with urban group $(\mathrm{p}=0.023)$.

It can be observed in Table 5 that $87.1 \%$ of the students from urban schools and $98.6 \%$ of the students from rural schools knew that excessive sun exposure in children can be a predisposing factor for skin cancer $(p=0.015)$. One of the questions in the questionnaire applied in this study related to the daily use of sunscreen and it was observed that $42.9 \%$ of students in the urban schools and $47.1 \%$ of those in the rural schools used sunscreen daily $(\mathrm{p}=0.011)$, representing an important contribution to the prevention of skin cancer.

The results reported herein show that the intervention applied in this study is a good strategy for raising the level of knowledge of students in both urban and rural locations and thus represents an important tool for reducing the risk of developing skin cancer in the future. This study highlights the importance of strategies for skin cancer prevention and promoting the use of sunscreens. The intervention was of great value in relation to disseminating knowledge on this topic.

\section{References}

Agbai ON, Buster K, Sanchez M, et al (2014). Skin cancer and photoprotection in people of color: a review and recommendations for physicians and the public. J Am Acad Dermatol, 70, 748-62.

Castilho IGS MAA, Leite RMS (2010). Sun exposure and risk factors for skin cancer: a review of habits and knowledge among university students. Anais Brasileiros de Dermatologia, 85, 173-8.

Crane LA, Asdigian NL, Baron AE, et al (2012). Mailed intervention to promote sun protection of children: a randomized controlled trial. Am J Prev Med, 43, 399-410.

Dermatology BSo (2014). Como prevenir o cancer da pele [Online].

Fernandes VDM, AA (2006). Comparison of the perception of both high school and middle school students from two Cianorte public schools in relation to the skin cancer causes. Arq Cienc. Saude Unipar, 10, 151-4.

Foletto MH, SE (2014). Cutaneous melanoma: new advances in treatment. Anais Brasileiros de Dermatologia, 89, 118-25.

Gefeller O, Li J, Uter W, et al (2014). The impact of parental knowledge and tanning attitudes on sun protection practice 
for young children in Germany. Int $J$ Environ Res Public Health, 11, 4768-81.

Gilaberte Y, Carrascosa JM (2014). Sun protection in children: realities and challenges. Actas Dermosifiliogr, 105, 253-62.

Hora CG PB, Martins S, Batista CVC, Siqueira R (2003). Avaliacao do conhecimento quanto a prevencao do cancer da pele e sua relacao com exposicao solar em freqüentadores de academia de ginastica, em Recife. Anais Brasileiros de Dermatologia, 78, 693-701.

Hunter S, Love-Jackson K, Abdulla R, et al (2010). Sun protection at elementary schools: a cluster randomized trial. J Natl Cancer Inst, 102, 484-92.

INCA NIoC-. 2014a. Cancer Incidence in Brazil - 2014 [Online].

INCANIoC-. 2014b. Exposicao ocupacional cancer relacionado ao trabalho [Online]. http://www1.inca.gov.br/situacao/ arquivos/causalidade_exp_ocupacional.pdf.

Jansen R, Osterwalder U, Wang SQ, et al (2013). Photoprotection: part II. Sunscreen: development, efficacy, and controversies. J Am Acad Dermatol, 69, 867 e1-14; quiz 81-2.

Klostermann S, Bolte G (2014). Determinants of inadequate parental sun protection behaviour in their children--results of a cross-sectional study in Germany. Int J Hyg Environ Health, 217, 363-9.

Kyle RG, Macmillan I, Forbat L, et al (2014). Scottish adolescents' sun-related behaviours, tanning attitudes and associations with skin cancer awareness: a cross-sectional study. BMJ Open, 4, 5137.

Marehbian J, Colt JS, Baris D, et al (2007). Occupation and keratinocyte cancer risk: a population-based case-control study. Cancer Causes Control, 18, 895-908.

Quatrano NAD JG (2013). Current principles of sunscreen use in children. Curr Opin Pediatr, 25, 122-9.

Rhee JS, Matthews BA, Neuburg M, et al (2004). Quality of life and sun-protective behavior in patients with skin cancer. Arch Otolaryngol Head Neck Surg, 130, 141-6.

Santos JOS AR, Souza SO, Lima LL, Costa EF, Oliveira PTMS (2007). Assessment of the level of information about the prevention of skin cancer in agricultural workers in the municipality of Lagarto, Sergipe. II Congresso de Pesquisa e Inovacao da Rede Norte Nordeste de Educacao Tecnológica, 2007 Joao Pessoa - Paraiba, Brasil.

Sattler U, Thellier S, Sibaud V, et al (2014). Factors associated with sun protection compliance: results from a nationwide cross-sectional evaluation of 2215 patients from a dermatological consultation. Br J Dermatol.

Stolzel FNS, Stefan Uhmann, Michael Baumann, Hendrik Berth, Jürgen Hoyer, Gerhard Ehninger (2014). Be smart against cancer! A school-based program covering cancer-related risk behavior. BMC Public Health, 14, 1-9. 